\title{
EL CASTELL D'ALMIZRA: DE HISN A CASTRUM
}

Por

VICENTE SEBASTIÁN FABUEL

El presente artículo muestra los trabajos de investigación realizados en el yacimiento del Castell d'A/mizra, a modo de estado de la cuestión, y con especial referencia a las dos últimas campañas.

Fueron, por el lado de la Corona de Aragón, el Rey Jaime I el Conquistador, y, por el castellano, el Infante Alonso, quienes en 1244 firmaron el «Tractat d'Almizra» para no hostigarse mutuamente y diseñar la frontera presente y futura entre ambos reinos; frontera que con el tiempo sufrió cambios sustantivos.

Este acuerdo, sus orígenes y consecuencias, ha sido tratado por varios autores de manera clarificadora; sin embargo hasta el presente, el castillo había sido apenas aludido. Mateo Box comenta que el alcaide del castillo era Abdallah-Marhop cuando en 1243 lo toma Nicolás Scals.

El Tratado de Almizra se impone como revisión de unas fronteras, ya rebasadas; en 1239 y 1240 ya se habian producido dos ataques aragoneses a Villena y Sax por los caballeros Ramón Folch, Arnal de Alagón y el infante Fernando de Aragón. Los castillos que jalonan esta frontera existen antes de establecida esta división de origen geográfico: para Castilla el llano y para la corona aragonesa el área montañosa. Tras la capitulación de Montesa de 1277 se abrió una profunda conquista de la zona meridional del Reino de Valencia, subsistiendo los musulmanes en alquerias subordinados a señores cristianos. En los castillos que se conservaron tras las sublevaciones musulmanas de fines del siglo XIII, se hicieron con frecuencia las reformas necesarias para sus nuevas funciones de tipo señorial. También las secuelas de la prolongada guerra castellano-aragonesa (1296-1304) originó cuantiosos daños y ruinas en la zona; se documentan quemas y talas contra las tierras del señorío de don Juan Manuel, en Villena. Restaurada la paz, Jaime II inicia la reparación y restauración de torres y castillos.

La fortificación y el hábitat medieval se vertebraría sobre la antigua Vía Augusta, 
de Xátiva a Elx por el Vinalopó, siendo la base de las alquerías las «villae rusticae» tardorromanas, originándose como fortificación a finales del siglo IX.

\section{El yacimiento}

Está situado en el término municipal de Camp de Mirra, a 73 kilómetros al NO de Alicante, coordenadas $38^{\circ} 40^{\prime} 51^{\prime \prime}$ - 20 54'13" (M.M.). Sus accesos lo constituyen la carretera comarcal Villena-Alcudia en su kilómetro 51 . La comarca tiene la vegetación entre carrascal y estepa. El rio Vinalopó, en cuya margen derecha se halla, es de régimen irregular y sufre un gran estiaje.

Desde la prehistoria los valles fluviales funcionan como vías de comunicación e intercambio, éste serviría de nexo entre el este y sur peninsular. Este territorio se ha definido también desde antiguo como zona de frontera entre llano y montaña, costa e interior, imponiéndose una importante necesidad de fortificación, de sincastillamento», siendo su evolución de asentamientos autóctonos fortificados antes de la romanización, a retornar a su funcionalidad tras la disolución del Estado romano, pasando por las vicisitudes de las luchas intestinas islámicas y sirviendo de guardián de la frontera sudoriental de Aragón.

El cerro de Sant Bertomeu, o Puig d'Almizra, con sus 665 metros de altitud sobre el que se ubica la fortificación, domina todo el amplio valle sedimentario del Vinalopó entre la sierra de Beneixama y la sierra de Onil. Desde la cima se tienen a la vista el castillo de Banyeres, puerta de la Sierra Mariola que conduce a Alcoi, y el castillo de Biar, guardián a su vez de los accessos a la Foia de Castalla.

Los restos del castillo se hallan en la parte superior del cerro. De su última época queda en pie una torre, de las dos originales, que sirve en la actualidad como dependencia-anexo de la ermita. Además de este núcleo en elevación sobre el cerro, son observables algunos muros en los sucesivos aterrazamientos del cabezo. El carácter estratégico del lugar es innegable y el topónimo árabe, Al-Misra, lo identifica plenamente: la frontera, los límites.

El Proyecto de Investigación se inició en 1982, con la colaboración de D. José M. a Soler, desarrollándose los trabajos en sucesivas campañas financiadas por la Diputación de Alicante, el Ayuntamiento de Camp de Mirra y la colaboración del Ayuntamiento de Valencia, dentro de sus campañas de Campos de Trabajo.

Los objetivos iniciales fueron delimitar la extensión del recinto y realizar el levantamiento planimétrico del yacimiento. El primer problema fue el que la mayor parte de las estructuras constructivas estaban cubiertas en algunos lugares por varias capas de relleno. La cantidad de éste da idea de las dimensiones del castillo original y de los materiales que participaron en su construcción, así como de que nos encontrábamos trabajando en la base misma de la fortaleza.

Desconocemos la existencia de referencias escritas anteriores a la conquista cristiana, perteneciendo la documentación existente a los siglos XIII, XIV y XV, a la que aludimos en la comunicación presentada al I.C.A.M.E. El carácter de corredor, de vía de comunicación y la riqueza del dominio natural, concibió desde antiguo una ocupación de la zona bastante importante. Una muestra de ello supone el hallazgo 
EL CASTELL D'ALMIZRA... / Sebastián
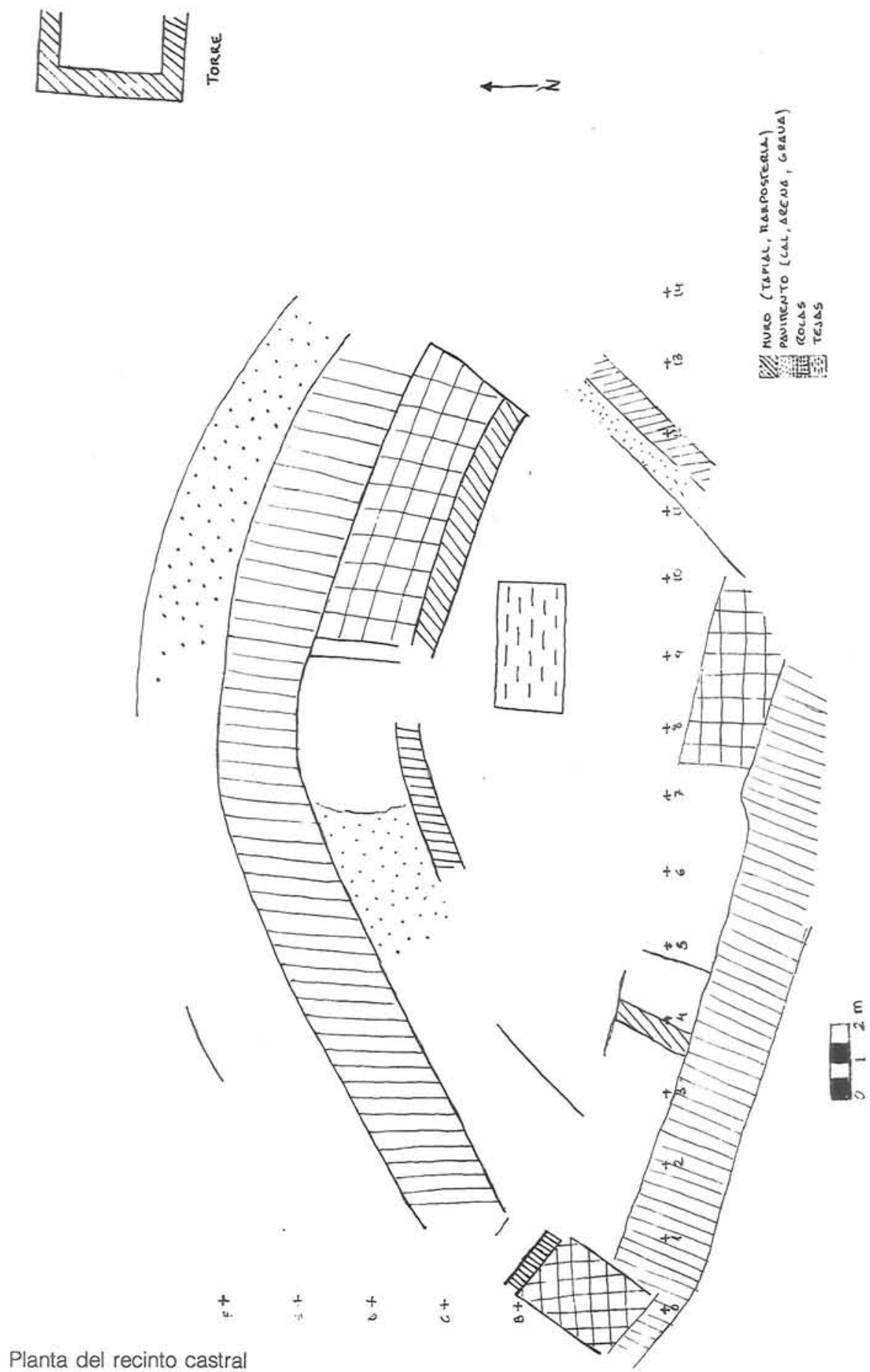

Planta del recinto castral

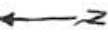

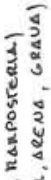

过 
de materiales relacionados con la agricultura y la industria correspondientes a la Edad del Bronce, así como cerámicas diseminadas por todo el recinto. De la misma época existe un yacimiento en el Cabezo de la Creueta en la Canyada de Biar, a dos mil metros hacia el SO del que nos ocupa.

Hacia el oriente del Puig d'Almizra existe otro de inferior altitud, «les Fantasmetes», en cuya ladera occidental y septentrional aparecen diseminados conjuntos alineados de piedra seca que pudieran haber correspondido a viviendas, o corrales (ibaqar?). Se trataría de chozas sin agrupación urbana. Tal vez el origen podría ser el de un poblado ibérico, aunque la realidad es la ausencia de cerámica superficial de la época que es lo sintomático. Estos muros, algunos de hasta dos metros de anchura, siguen las curvas de nivel, y el estar arruinados podría tambien deberse a que el barro que hiciera de nexo se haya diluido. Estas formaciones lineales también podrian haberse realizado para evitar los arrastres de tierras ejerciendo de muros de contención. Respecto a éstas hoy por hoy ni podemos precisar más por falta de prospecciones. En la cota más elevada de este cerro se halla una estructura rectangular de piedras y argamasa, base de una torre atalaya que serviría como apoyo al recinto principal, pues desde aquél la visibilidad queda parcialmente menguada. La cata realizada proporcionó fragmentos de gran vasija con aro de refuerzo y otros de decoración impresa, de cronología muy similar a los hallados en el castillo. La conservación de esta torre de guaita no habría sido posible debido a su utilidad temporal y al carácter modesto de sus materiales constructivos. La roca aflora con gran rapidez, mostrando que nos hallamos prácticamente sobre la estructura básica.

A medio camino entre un cerro y otro existe una cantera y una vaguada en dirección sur al Vinalopó, en cuyo suelo existen unas insculturas o «petroglifos» que describen cruces a la manera gótica, regueros serpentiformes, escudos barrados o cuarteados. Este lugar se denomina «es Graelletes», por la similitud a parrillas de algunas de sus formas. Existe cierto paralelismo entre algunas de las figuras y las cruces esculpidas en roca del castillo de Ademuz (Valencia).

La cronología de ocupación del lugar correspondería inicialmente a la Edad del Bronce, y la reocupación, reutilización, se produciría desde el siglo IX-X hasta el XIV. A partir de estas fechas la función militar-defensiva dejaría de tener sentido. Esto iniciaría un proceso de arruinamiento, con el consiguiente aprovechamiento de los materiales de cara a otras construcciones, como la ermita que se alza a lo largo del siglo $\mathrm{XVI}$, o las casas del valle. El único vestigio constructivo que permanece, podemos decir que íntegro, ya de época cristiana, es la torre cuadrada de $475 \mathrm{~cm}$. de lado y 12 metros de altura aproximadamente, a la que se adosó la ermita de San Bartolomé. Presenta sillares en las esquinas y mampuesto en los paños intermedios. En su parte inferior y hasta los dos metros la composición del muro es de sillarejo irregular. En cierto sentido podría ser considerada como casa-torre dentro de la tipología de construcción semiseñorial rural. Este edificio ha sufrido diferentes intervenciones para adaptarla como vivienda de ermitaño, que han afectado tanto a su configuración exterior como a su disposición interna.

Varias campañas de excavaciones se han realizado desde 1983, habiéndose echado en falta fuentes iconográficas relativas al castillo que dificulta su reconstrucción histórico-tipológica. El material constructivo alterna el mampuesto, a base de piedras poco o nada labradas unidas con argamasa, y el tapial. Antes de comenzados 
los trabajos eran evidentes algunos muros internos y una gran brecha en el muro NE que podría corresponder a un antiguo acceso.

Diversos eran los problemas que se planteaban y que exigian respuesta arqueológica: el origen de la fortificación y dinámica del asentamiento, tipología de los elementos murarios, perímetro y matriz cultural de los mismos, funcionalidad del espacio interno..

El recinto amurallado encierra un polígono irregular de, aproximadamente, 400 metros cuadrados, que alcanza su máxima longitud en el lado oeste. Este recinto tiene tanto relleno y las hiladas superiores de los muros están tan destruidas, que las partes de la muralla que se conservan desempeñan la función de muro de contención; precisamente por ello su aparejo exterior es difícilmente observable. En algunos lugares se observa la composición del tapial, y en otros pequeñas losas situadas oblicuamente que dan un aparejo próximo al «opus spicatum». Cuando ha saltado el enlucido exterior deja ver los mechinales del encofrado. El espesor de los muros lo calculamos alrededor de los dos metros. En el muro meridional no se ha utilizado el tapial sino adobe dispuesto horizontalmente, yeso, cantos y trozos de tegula. Se realizó una cata en el muro norte por el interior, no hallando fragmentos cerámicos que facilitaran su fechación. La estratigrafía mostró un gran nivel de piedras caidas envueltas en argamasa; bajo éste, aparece un pavimento de grava y cal sustentado por una capa de arcilla. En el nivel inferior otro similar al primer pavimento y bajo él una capa de cenizas y tierra muy oscura. Entre ésta y la roca, un conglomerado de tierras y piedras sueltas. La profundidad máxima alcanzada fue de 2'30 metros.

La primera tarea realizada fue la cuadriculación de todo el conjunto mediante un eje de coordenadas con cuadrículas de $2 \times 2$, una vez elegido el punto 0 y desbrozado el recinto. Los trabajos realizados en el sector norte sacan a la luz cuatro compartimentos, cuyos muros se asientan directamente sobre la roca. Estos muros medianeros tienen $60 \mathrm{cms}$. de espesor por término medio, ya que son de desigual factura y dirección.

La estratigrafía del yacimiento presenta los siguientes niveles de diferente grosor y composición según el área excavada: tierra vegetal, capa de destrucción de los muros, capa de destrucción de la techumbre, suelo de hábitat y arcilla, y desconchados de roca estérii.

\section{Los materiales}

Si hemos tenido en cuenta la tipología de la construcción y los documentos, debemos ahora observar los materiales, sobretodo la cerámica por su carácter de indicadores de cronología.

Los primeros elementos, los más antiguos, que aparecen son pertenecientes a una cultura agrícola cerealística y encastillada como la Edad del Bronce, también se debe tener en cuenta que a lo largo de los siglos VI y VII, y posteriores, existe una decadencia cultural observable en el empobrecimiento tecnológico, en el que la cerámica facturada a mano tiene una gran importancia asemejándose a la realizada en la Edad del Bronce. 


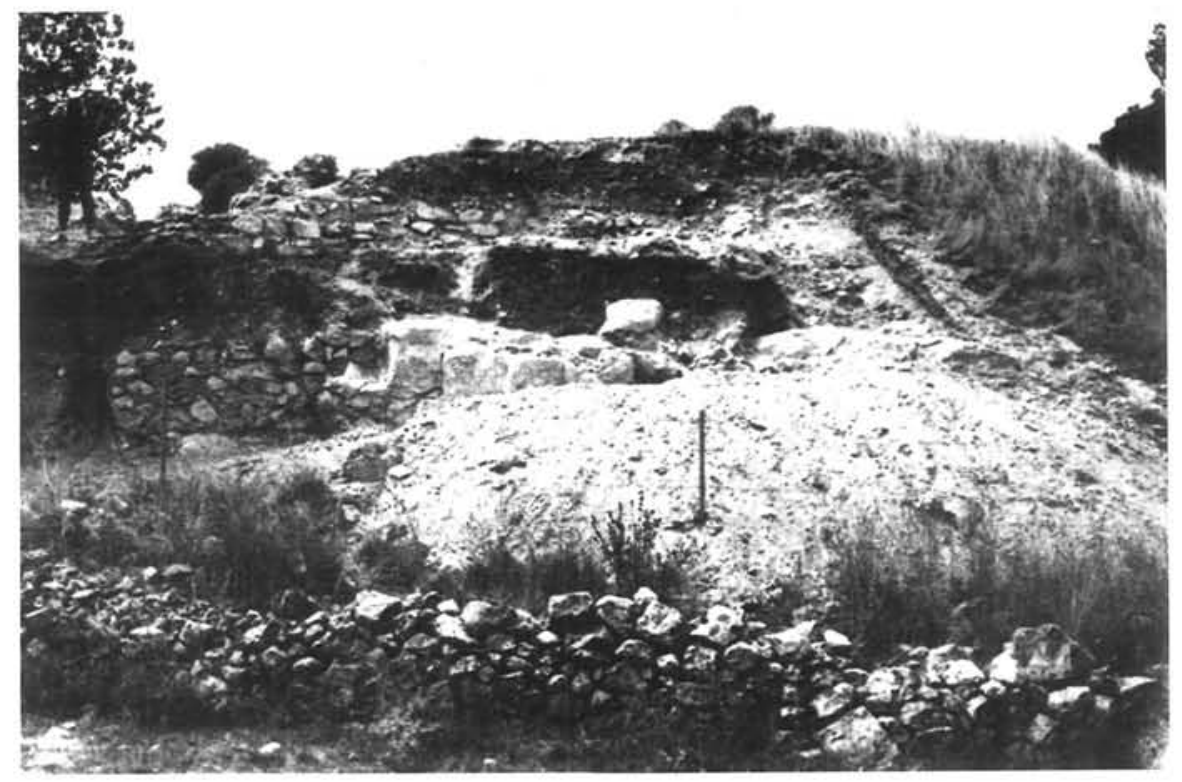

Muros norte 
EL CASTELL D'ALMIZRA... / Sebastián

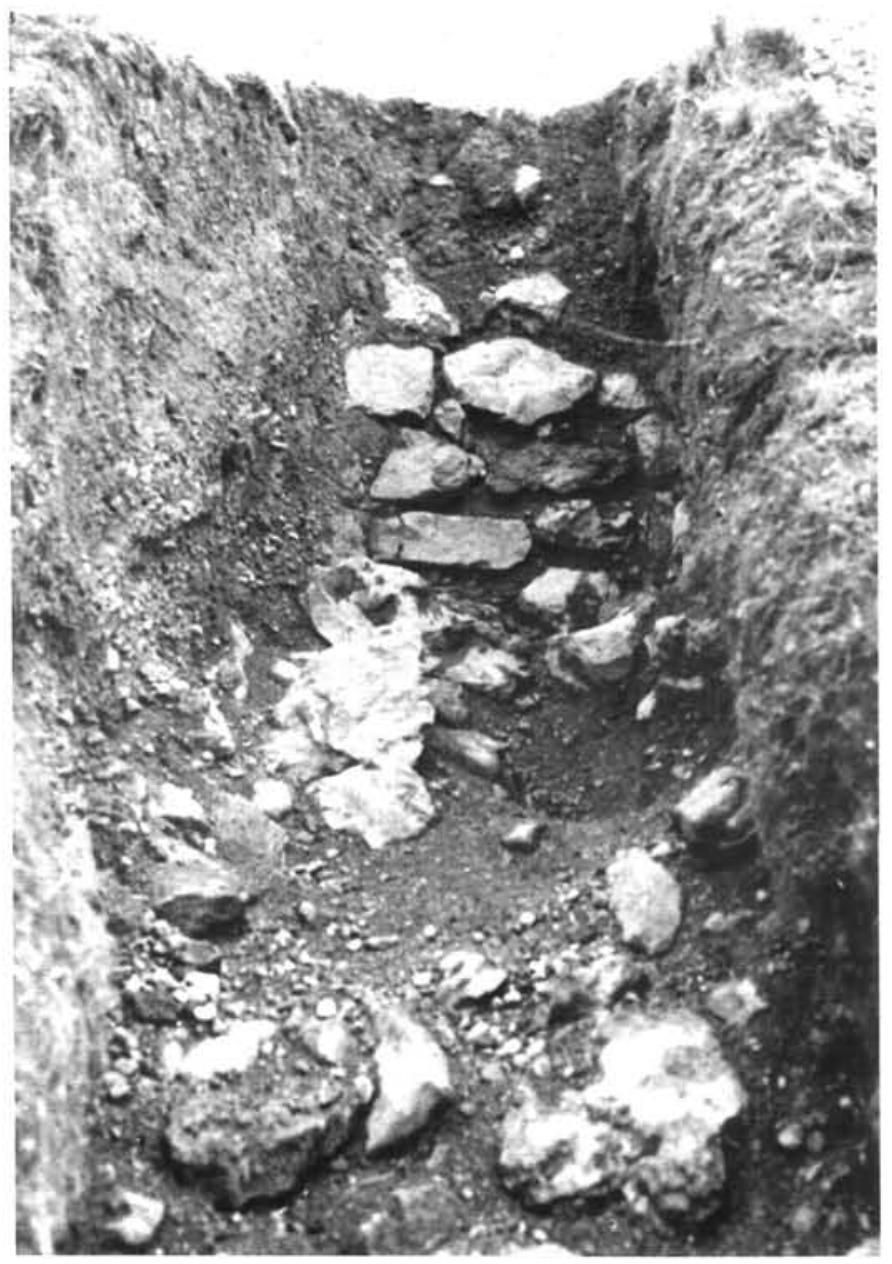

Aspecto de la trinchera del muro superior norte 


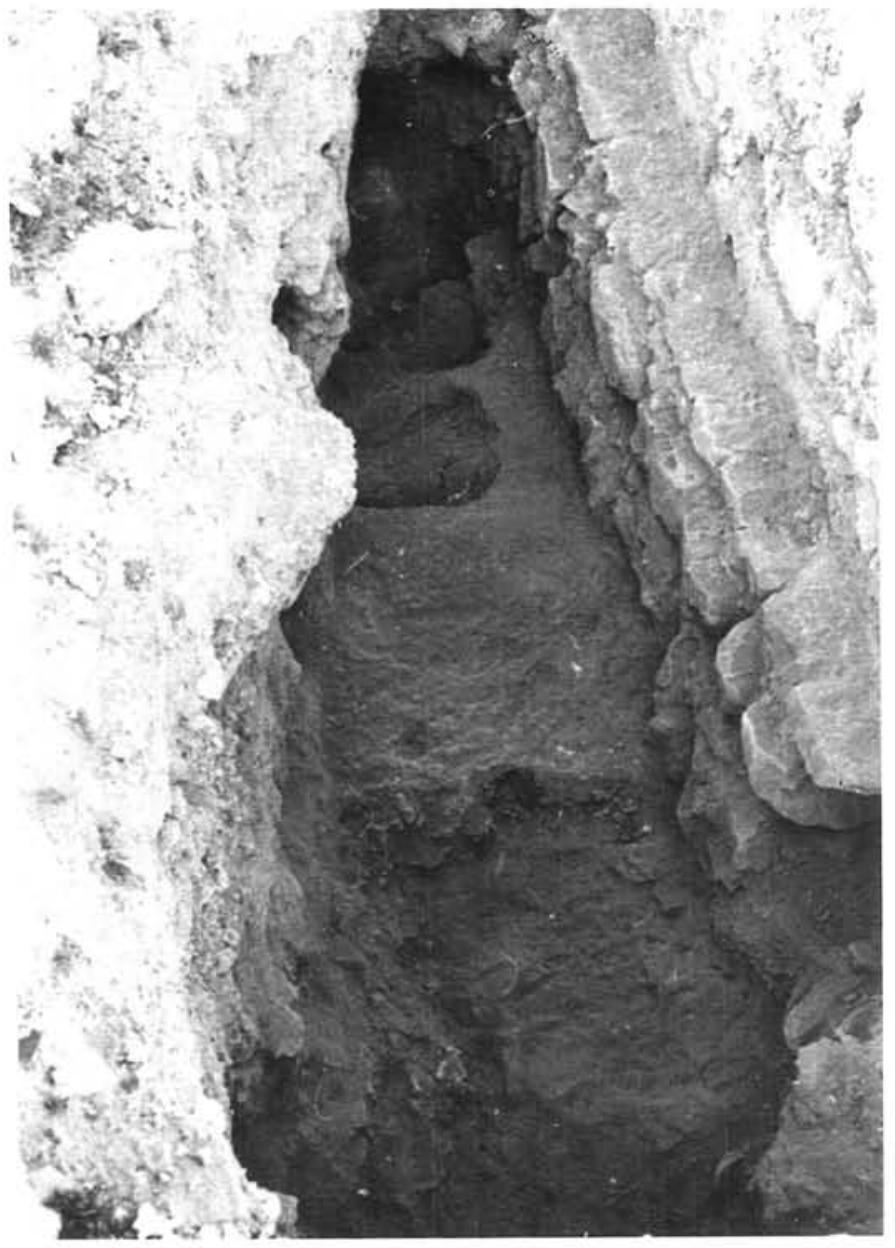

Aspecto de pavimento y base del muro este 
Los materiales líticos hallados han sido: molinos de mano, piezas de sílex, piedra de base de pilar de madera, alisadores.

Respecto al material óseo, muy variado con predominio de las especies ovina y caprina, también de aves y roedores. Estos interesantes indicadores económicos están a falta de estudios más en profundidad. Algunos presentan signos de preparación y utilización (botones y cuentas, plaquetas y mango de cuchillo o de rueca). Son los remaches y los fragmentos de clavos lo más importante del material metálico. Respecto al bronce aparecen: pinzas y unas varillas sin determinar.

El vidrio ha aparecido a lo largo de todo los cortes, y siempre con fragmentos pertenecientes a pequeños recipientes (cuellos, galbos, asas).

En la cerámica y amén de las pesas de telar de barro cocido, la mayor presencia se refiere a la no decorada. Dentro de ésta suma una buena parte la realizada a mano (vasijas hemiesféricas, ovoides, de perfil aquillado). De las facturadas a tornos son muy abundantes los grandes envases, algunos con aros de refuerzo (simples o con digitaciones, ungulaciones...). Los tipos son variados: ollas, escudillas, ataifores, tinajas, tapaderas, jofainas, cántaros, lucernas, platos, fogón, trípode y cazuelas. Algunas de estas formas presentan vidriado. Las tejas aparecen en todo el recinto y con marcada abundancia, habiéndolas con ungulaciones externas.

La vajilla decorada lo es con impresiones (signos cúficos, estrellas...), de cuerda seca, esgrafiada, verde morado, pintada con líneas rojas o negras o blancas, incisa (peinada, ungulada, digitada) y reflejo dorado. El arco cronológico de las producciones cerámicas medievales recorrería desde el siglo XI al XV. Cronología que se vería reforzada por la tipología de los otros objetos hallados.

\section{Campaña de 1986}

Los trabajos continuaron en la línea de buscar una clara estratigrafía, restos de estructuras que posibilitaran el mayor conocimiento de la distribución espacial interna. La intervención se desarrolló principalmente en las áreas central y meridional.

Estos trabajos aportaron pocas novedades respecto a las campañas anteriores, tanto respecto a la distribución de niveles estratigráficos como a la tipología de los hallazgos.

El esquema estratigráfico que se repite con ligeras variaciones en el yacimiento consiste en un nivel superficial de tierra muy suelta, con mantillo orgánico y mezcla de tejas y fragmentos cerámicos. El siguiente nivel corresponde a derrumbre: piedras sueltas, tejas y materiales revueltos, carboncillo. El tercer nivel, el de ocupación, de tierra apisonada, arcilla, cal y guijarro, unos con base de piedra y otros no. En algunos casos los niveles de ocupación se superponen. Bajo ello la roca viva.

Se han puesto al descubierto dos espacios internos: uno, el aljibe (ab8/9/10), y otro, un pequeño bastión esquinero que se elevaría sobre la estructura actual (a7).

Los objetivos referidos a la delimitación y puesta al descubierto del espacio defensivo murario: se trabajó sobre los lienzos norte y sur, y en la búsqueda del acceso al núcleo castellano. El segundo objetivo no se cumplió, pero respecto al primero podemos decir que en el caso de la muralla norte se ha puesto al descubierto un 


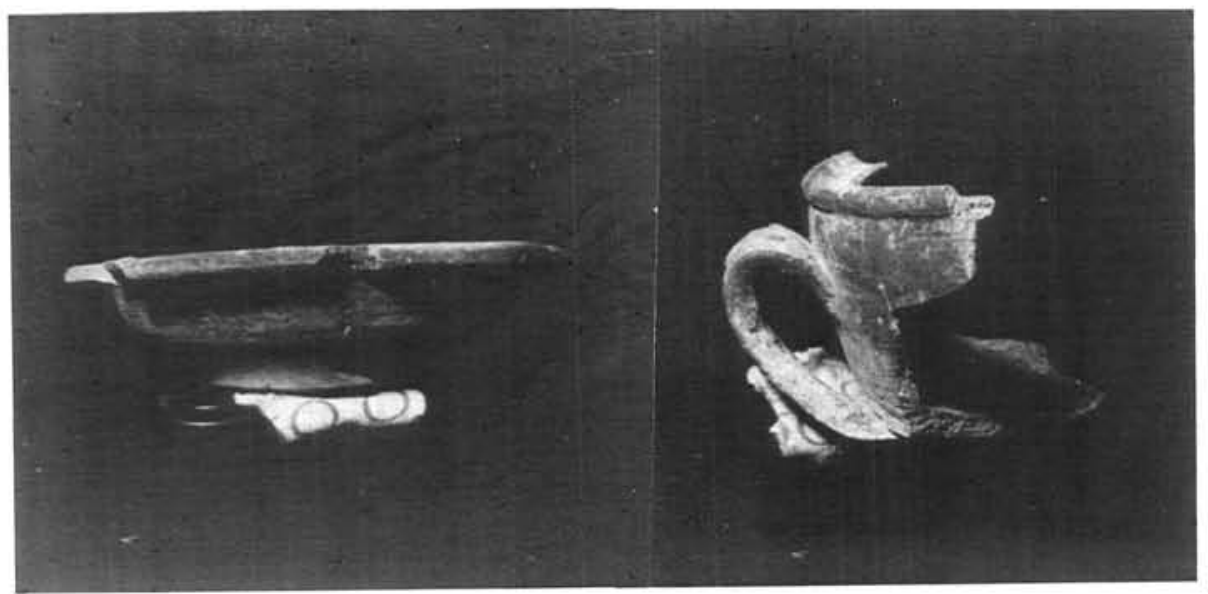

Materiales cerámicos 
EL CASTELL D'ALMIZRA... / Sebastián

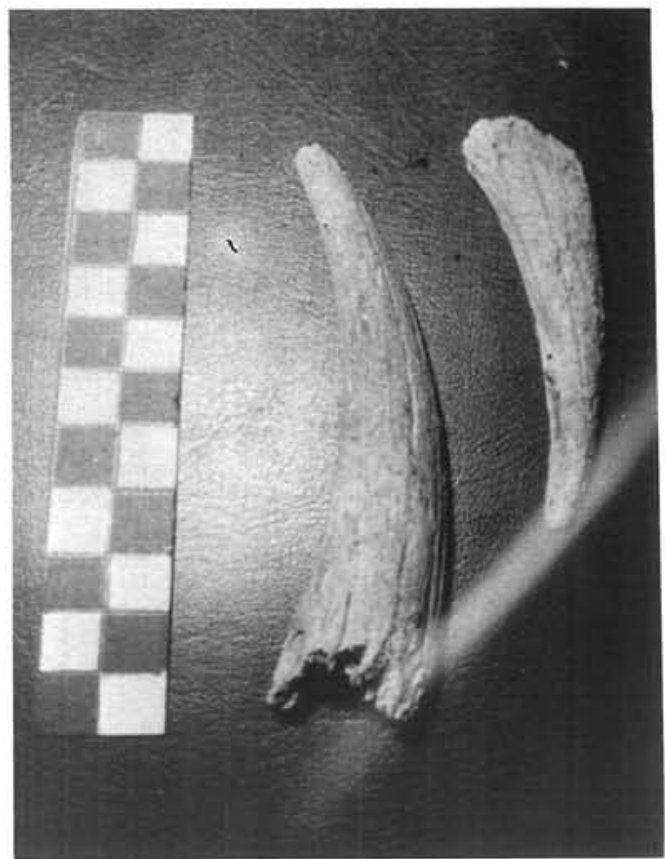

Materiales óseos
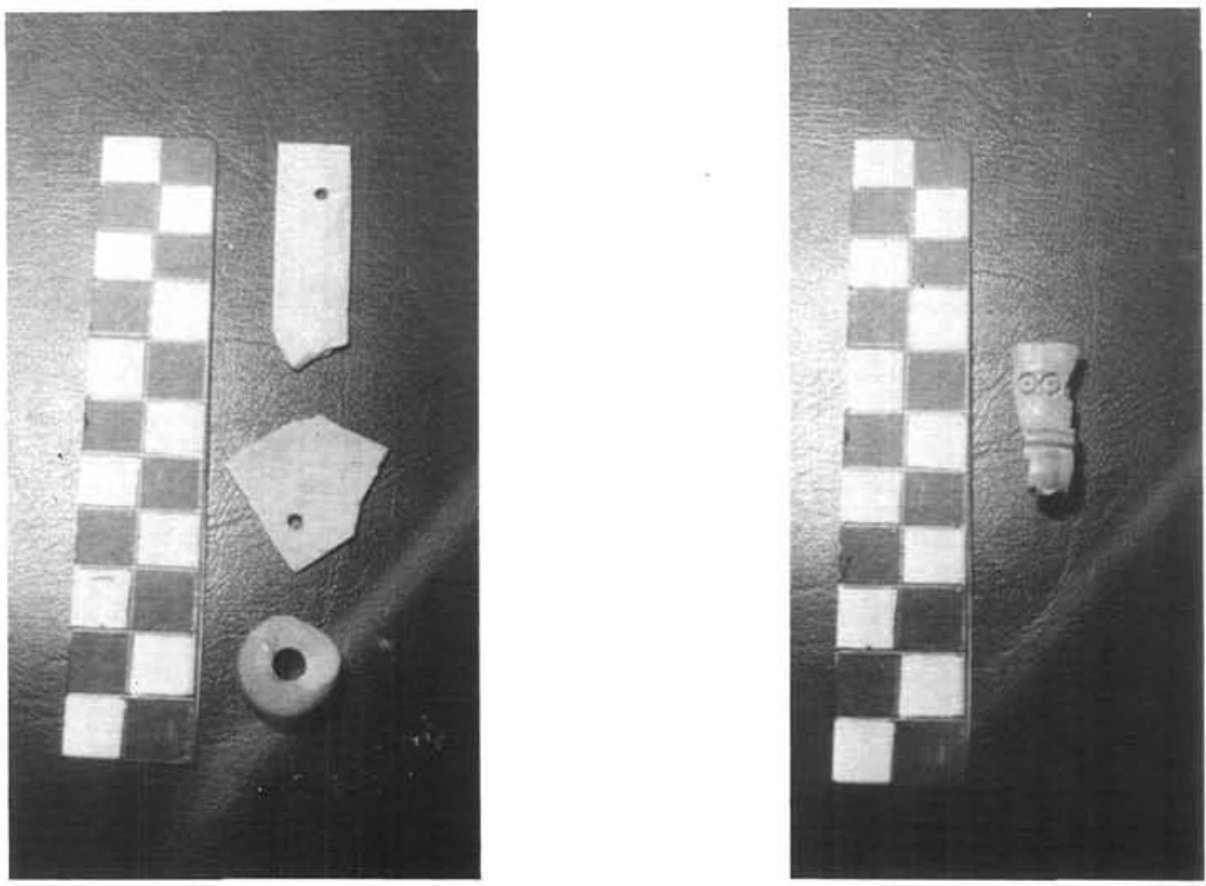
doble muro escalonado y un piso de argamasa a modo de ronda. En el muro sur se alcanzó la roca, con lo que el perímetro queda ya dibujado en ese área.

Respecto a los materiales hallados, éstos no difieren tipológicamente de los ya obtenidos en anteriores campañas, aunque cuantitativamente destacan los existentes a lo largo del "corredor de ronda» de las defensas norte.

\section{Conclusiones}

Es evidente que mientras el yacimiento no sea excavado en su totalidad cualquier conclusión resultaría aventurada y no pertinente. No obstante existen datos indicadores que no pueden ser pasados por alto.

El interés del yacimiento se fundamenta en la mutación que sufre por el cambio de condiciones políticas, sociales y económicas tras la conquista; $y$, anteriormente, por su papel de testigo en la reformulación territorial de este área geográfica.

La tipología y factura original de las obras muestra la inexistencia de edificaciones susceptibles de ser utilizadas como residencia nobiliar. Esta reorganización del castillo es paralela al establecimiento de estructuras señoriales que únicamente corresponden a la organización territorial, no a la organización de la sociedad o la ocupación del suelo en época musulmana, momento en el que la comunidad rural dispone de un edificio castral y de un territorio comunal intrínsecamente ligados.

Los «husun» de la cuenca del Vinalopó se construirian principalmente a lo largo del siglo XII, en período almohade; el califa Yusuf al-Mu'min fortaleció esta zona de frontera, y se caracterizan por tener un pequeño recinto amurallado, poligonal, de elevados y gruesos muros y en el interior una torre de planta cuadrada de tapial. Con la conquista cristiana aparece la sillería en los refuerzos y la mampostería en los entrepaños. En el siglo XIV, con la pólvora, los edificios se reforzarán con chapas de piedra, zapas, aberturas.

El asentamiento, no el fuerte, en el cerro debió haber desaparecido a partir de finales del siglo XIII. Tenemos el testimonio arqueológico y documental de las modificaciones introducidas en la sección central, que había pasado a ser centro de poder señorial o real y que contaba con una pequeña guarnición. En el mundo medieval, marcado por una geopolítica móvil e incierta, la distancia entre dos fuertes no suele superar diez kilómetros. Estas construcciones actúan de refugios, más protegidos por una muralla que por abruptos naturales, enmarcándose su construcción dentro del proceso de encastillamiento realizado a lo largo de estos siglos.

Los investigadores han venido definiendo en los castillos valencianos unos índices de arabismo que podrian ser aplicables al nuestro: larga estructura poligonal que delimita el castillo sin aspilleras, mampuesto, tapial, cisterna. Respecto a su funcionalidad lo vemos asociado a un hábitat rural permanente, castillo-refugio, sin importantes construcciones internas, escasos vestigios en el suelo difíciles de interpretar, sobre una colina que supone una defensa natural pero que también cumple la condición de accesibilidad para la población; guardián de una zona fronteriza, de control de paso del viario del valle, y dotado de una pequeña guarnición. En el llano existiría alguna «torre de vila», similar a la de Beneixama, como en la huerta de Valencia, pequeños edificios situados en medio de las alquerias. 
Siendo Biar el castillo más fuerte y meridional de esa frontera del SW, el realizar la entrevista en Almirra entre el Rey Jaime y el Infante Alfonso, introducía a éste en terrirtorio aragonés. No sólo supuso el Tratado el que una guerra inminente fuera evitada, sino que también supuso el abandono definitivo de la apelación por parte de la iglesia de Toledo en lo referente a la confirmación del Obispo de Valencia, Arnau.

Es extremadamente difícil formular una definición de la última fase del desarrollo de un tipo de fortificación en un país. Si queda meridianamente claro el porqué se erigió en este lugar, cabría preguntarse ¿por qué dejó de utilizarse? El fin de un castillo es pocas veces un suceso breve y decisivo pero aún así si el castillo tiene una razón de ser será reconstruido. Los documentos cristianos nos hablan de esta etapa final: (1260) «Arnau de Montsó alcaide y arrendador de impuestos de los castillos de Biar, Almizra y Beniamar»; (1263) «Gil Sanç d'Alagó, alcaide de Bañeres y Serrella», ¿lo fue también de Almirra y Benejama?; (1356) «Testamento de Diego Descalç i Salcedo». La decadencia del «Castell de Almizrra» estaría ligada a un proceso de cambio, en lo militar y en lo sociopolítico, en este área territorial.

\section{BIBLIOGRAFIA}

AZUAR RUIZ, R. (1985): «Castillo de la Torre Grossa (Jijona)».

AZUAR RUIZ, R. (1985): «Excavaciones medievales en el Castillo de la Mola (Novelda, Alicante). I. Las cerámicas finas (siglos XII-XV)», Novelda.

BARCELÓ TORRES, C. (1982): «Toponimia aràbiga del País Valencià, Alqueríes i Castells». BAZZANA, A. et alii (1988): «Les châteaux ruraux d'Al-Andalus».

BURNS, R.I. (1982): «El Reino de Valencia en el siglo XIII. Iglesia y Sociedad».

BURNS, R.I. (1987): «Colonialisme medieval».

BURNS, R.I. (1987): «Moros, cristians i jueus en el regne croat de València». «Crónica».

DEL ESTAL, J.M. (1982): «Conquista y anexión de las tierras de Alicante, Elche, Orihuela y Guardamar al Reino de Valencia por Jaime II de Aragón», Alicante.

EPALZA, M. de (1984): «Funciones ganaderas de los albacares en las fortalezas musulmanas», Sharq al-Andalus, 1.

GUICHARD, P. (1982): «Los castillos musulmanes del norte de la provincia de Alicante», Anales, n. ${ }^{\circ} 1$.

GUICHARD, P. (1984): «El problema de la existencia de estructuras de tipo feudal de la sociedad de Al-Andalus», Estructuras feudales y feudalismo en el mundo mediterráneo.

GUTIÉRREZ LLORET, S. (1988): "Cerámica común paleoandalusi del sur de Alicante siglos VII al $X_{\gg}$.

HUICl (1976): «Documentos de Jaime I de Aragón».

LLOBREGAT, E. (1970): «Castillos y fronteras medievales en la provincia de Alicante», Castillos de España, n. ${ }^{\circ} 70$.

MARTINEZ FERRANDO (1934): «Catálogo de la documentación relativa al Antiguo RV». ROCA (1977): «Inmigración a la Valencia medieval», BSCC LIII. 
RUBIERA, M.J. (1985): «Villena en las calzadas romana y árabe».

SEBASTIÁN, V. (1985): «El castell d'Almizrra», I CAME.

SEBASTIÁN, V. (1987): «El castell d'Almizrra. Campaña de 1985», II CAME (1848) «Trovas de Mossén Jaime Febrer». 